\title{
Exploration of Hong Kong, Macao and Taiwan Graduates Training Mechanism
}

\author{
Yongqian Li \\ College of Management, Jinan University, Guangzhou, China \\ Email: 815524537@qq.com
}

Received 23 June 2015; accepted 11 July 2015; published 14 July 2015

Copyright (C) 2015 by author and Scientific Research Publishing Inc.

This work is licensed under the Creative Commons Attribution International License (CC BY). http://creativecommons.org/licenses/by/4.0/

c) (i) Open Access

\begin{abstract}
Graduate education is an important part of higher education, which is related to national innovation plan. Much attention should be paid to the core ingredients that reflect the level of higher education. This paper studies the Hong Kong, Macao and Taiwan graduates training mechanism, from the aspects of enrollment links, quality assurance, degree in management and policy support specifically addressed.
\end{abstract}

\section{Keywords}

\section{Graduate Training Mechanism, Internationalization, Comparative Study}

\section{Introduction}

The graduate education is at the top of national education and embodies the higher education quality and feature of one country. Hong Kong, Macao and Taiwan areas are affected by the capitalism culture. The training modes of their graduate have common features and distinct features and integrate localization and internationalization.

\section{Highly Independent and Fair Enrollment of Graduates}

The graduate enrollment is at the front in graduate training. An enrollment mechanism will determine the graduate source. Enrollment can determine the sources, structure and quality of the graduate. Hong Kong, Macao and Taiwan sticks to the rule of relaxed enrollment and strict graduation, avoids single examination regulation, focuses on investigation of the academic capability of students, academic merit and innovation capability of graduates, and highlights skill potentials in the professional foundation. Hong Kong, Macao and Taiwan have their own features.

No uniform enrollment examination is for graduates in Hong Kong. Application is required. The main procedure is described as follows: an applicant should first fill the enrollment application, provides the college gradu- 
ation certificate, bachelor's degree certificate, score bill in college, and related certificates for proving English level recognized by Hong Kong, and should be recommended by two professors. After agreed by the Academic Committee, if necessary, a tutor can request interview for enrollment. In addition, the enrollment time is not strictly restricted. A graduate can fully select it according to actual conditions (Wang, 1997), such as flexible permission mechanism can drive internationalization and diversity of the graduate education in Hong Kong.

The Macao special zone High Education Institution draft regulates that the applicants with equivalent degree, who are awarded the academic organizations of colleges of the courses and have learnt the courses for master degree, can first apply to learn the courses for the graduate degree. The applicants, who have the master degree or equivalent degree, or the bachelor's degree and have excellent academic research potential, can apply to learn the doctor's academic degree courses. In addition, the colleges in Macao with the master and doctor degree courses can prepare the graduate enrollment institutions.

The colleges with the graduate training qualification can independently enroll graduates in Taiwan. The enrollment task is regulated by the research institute of the colleges. Examination is selected by colleges. The examination subjects, contents and time are not uniform. In addition, the graduate enrollment examination is divided into graduate class and doctor class in Taiwan. Different colleges will be responsible for examination issues according to related regulations prior to enrollment examination every year. "Key for approval in gradate and doctor class enrollment of colleges" issued by the education department of Taiwan in 2011 regulates as follows: A college should specially found a special college-level enrollment committee, which will be responsible for the whole enrollment procedure, e.g. the enrollment quota reporting procedure, student application qualification, enrollment mode, examination calendar, enrollment rule and enrollment dispute handling method and other issues. The above issues should be described in details in the enrollment brochure.

To compare the enrollment institution of gradates in Hong Kong, Macao and Taiwan, the results are described as follows: first, enrollment embodies independence and fairness in Hong Kong, Macao and Taiwan, ensures internationalization of the graduate sources, and deeply reflects public properties of graduate education in Hong Kong, Macao and Taiwan. A citizen can fair compete to accept the higher graduate education, which is necessity for development of a modern higher education. Secondly, the enrollment modes are slightly different in Hong Kong, Macao and Taiwan. Colleges have no examination institution in Hong Kong and require application to ensure fair and just election of talents. Compared to other modes, the examination institution will obey some rules in operation, but the application institution is more flexible and can better embody independence of colleges and students. The application institution can completely survey comprehensive quality of a bachelor's graduate, can cultivate diversified top-level innovative talents, is a highlight in enrollment in the graduate education mechanism in Hong Kong, and can fully match the internationalization.

\section{Multiple Distinct Measures in Quality Guarantee}

The colleges in Hong Kong, Macao and Taiwan regard graduate training quality as the root. Multiple measures are taken to ensure graduate training quality and effective methods are adopted. They should be referred by the mainland.

To ensure graduate training quality in Hong Kong, colleges prepare strict academic control specification, which should be obeyed by the tutor and graduate. E.g. generally all colleges hold a qualification examination in one year after graduate enrollment to test the professional foundational knowledge level, science and research capability and academic potential of students and eliminate unqualified graduates. This examination features high election level, so students will have bigger pressure and can not waste time for a certificate. In addition, the academic ambience is very stronger in Hong Kong colleges. Different academic activities are very rich. A graduate should attend certain academic reports and academic activities during learning. E.g. subject activities organized by a tutor. A graduate should conduct fierce discussion in this activity. Students must attend the academic exchange meeting organized by the student department. Each graduate must report his research work, including introduction of new opinions, methods and discoveries in individual research, and point out contributions. In addition, the graduates in learning can have opportunities to attend international academic meeting, exchange with experts and scholars closely, report the research experiences and achievements to them, answer their questions, and hear their recommendations. To guarantee that graduates can attend such academic activities, colleges provide about 20,000 yuan for conferences. When graduates prepare the paper, the college will organize the oral defense committee for the paper. The members of the committee include the teachers from Hong Kong and foreign counties and have authoritative influences in their professional fields. If the paper can not reach the specified 
level, graduates will fail to pass this oral defense. Some nearly rigorous academic standards are prepared to control quality in graduate training in Hong Kong. Although graduates are not required to publish the paper in some periodicals like the graduates in mainland, if the graduates do not publish their research achievements in the international first-class periodicals, the opportunities to achieve the doctor degree are very few.

In Macao, after graduates are enrolled, their research capability of graduates is highlighted, therefore, graduates should have solid professional quality, grasp advanced theory, and smoothly conduct research on graduate learning phase. Like colleges in Hong Kong, the colleges in Macao will also hold examinations during graduate learning in order to grasp learning and research trend of graduates. The failed graduates will not have opportunities to prepare the paper. Like Hong Kong, internationalization is also highlighted in graduate training of colleges in Macao and teaching is open, which is common in graduate training in Hong Kong and Macao. If graduates want to smoothly graduate in Macao, they should publish some research papers or their research achievements in the international periodicals of their specialties.

Graduate quality is ensured from the globalized view in Taiwan. The graduate training quality keeps abreast of international level, e.g. the graduates are classified and diverted in training. No uniform standard is used. The tutor team is introduced to exert collective intelligences. The graduate course design is optimized to improve knowledge structure and capability structure of graduates. Teaching methods are reformed to cultivate learning interests of graduate. In addition, teacher quality is actively improved to meet the public demand for higher graduate education. E.g. Taiwan Yuan Ze University requires that the graduates should select the paper tutors before the first year in graduate training of the Motor Department. The paper tutors should have a title higher than the assistant professor of the specialty. The paper titles of graduates should be consistent with the specialty research direction of the tutors, or be based on the existing lab devices, so these professors can truly instruct graduates' paper heartedly, which is the first step for high paper quality and is also one highlighted features in Taiwan colleges. In addition, the technology English is a compulsory course in the Mechatronics Engineering Department of Tanwan Yuan Ze University, so it can assist graduates to train the knowledge and capabilities in English hearing, speaking and reading. Before a student graduates, he must complete paper and pass the strict oral defense. Research performance is established in nearly all areas in Taiwan, most graduates will publish the paper during learning, including international well-known periodicals.

The graduate quality guarantee measures are relatively mature in colleges in Hong Kong, Macao and Taiwan. Graduate quality guarantee measures in Hong Kong are integrated into the international graduate training practice. The graduate quality keeps abreast of the international level in Taiwan and Macao. The graduate training quality is very competitive on the international market in Hong Kong, Macao and Taiwan, so it is recognized widely in the world. The main reason is that the academic ambience of the colleges in Hong Kong, Macao and Taiwan is pure. The bad academic behaviors will be punished strictly. A scientific academic evaluation institution is established. Graduates and tutors can actively obey a series of academic rules, so the persons, who want to waste time for a certificate, will not survive.

\section{Scientific and Flexible Degree Management}

One key feature in graduate training mechanism in Hong Kong, Macao and Taiwan is that colleges focus on degree management in Hong Kong, Macao and Taiwan. Colleges prepare scientific and flexible management regulations and form the relaxed and strict management mechanism, which can meet the urgent demand of extensive students to accept higher graduate education, can ensure graduate training quality and level of graduate certificate, and avoid certificate depreciation

Graduate management is relatively relaxed and practicable in Hong Kong. On the one hand, graduates studying in Hong Kong colleges will closely contact tutors, have many opportunities to exchange with the department, graduate division and graduate association, and are permitted to attend some activities conducted by the graduate association. The graduate association is a non-official organization in Hong Kong and will organize some activities unrelated to academic research, e.g. recreational and sports activities, interview and tourism, and match, in order to enrich amateurish lives of graduates. On the other hand, the colleges focus on degree management of graduates in Hong Kong. The subjects and courses and graduate scale in Hong Kong colleges depend on the market demand, namely graduates can smoothly find a job after graduation. It embodies the humanization of graduate education in Hon Kong and is extensively welcomed by students (Fan, 2007). Based on this idea, colleges set up the courses like the general education in Hong Kong to broaden the students' vision, culti- 
vate their comprehensive thinking capability, and make students have broad recognition on the subjects outside the specialty, so the students will not lose in the rapidly shifting modern society. It embodies practicable trend in graduate degree management of Hong Kong colleges. Such practicable trend does not indicate relaxed requirements for academic capabilities and levels of students. Based on this idea, the graduates cultivated by Hong Kong colleges have wider vision and solid research capabilities.

Graduate management is relaxes in Macao. The highlighted feature is that the higher education law of Macao regulates whole-process management based on the examination committee. This law regulates that a coordination mechanism is established in master and doctor education. When some courses are required for master or doctor degree, the academic organization or research center will coordinate to set up the courses. Colleges should set up the master or doctor degree courses together with other higher education organization, therefore, this higher education organization should sign the coordination method with the university (Macao Higher Education Law, 1994). To set up master or doctor degree course, a college should sign cooperation agreement with public or private education organizations or research institutes in local area, Portuguesa, PRC or other countries or regions. The graduate training coordination mechanism in Macao area is like exchange mechanism in Hong Kong, but the coordination mechanism is a compulsory institution in Macao.

In Taiwan there are various management forms of graduate degree. Take the doctor graduate education as an example. In Taiwan universities and colleges all implement the strict tutorial system. In Taiwan it is stipulated that the number of doctoral students guided by each professor shall not be more than five, but in fact the schools have different implementation. Because of the difference in the nature of major, public and private university and teachers, as well as the professors shared by department and institute, tutor's guidance of the doctoral students is varied by school, and some professors have heavy teaching or scientific research tasks. However, relatively speaking, in the institutes with good professors, doctoral students can obtain more guidance and advices, and the education quality is relatively good. In addition, in Taiwan area the theses of doctoral students are required to be original. After completing the courses, the doctoral students shall take the qualifying examination. The qualified students shall work on the thesis. Before writing, the research is required. The research methods, data sources, article structure, research results and research innovation of doctors' theses must meet the requirements.

\section{Policy Support}

Hong Kong, Macao and Taiwan belong to the areas with developed higher education. People's education level is relatively high. The three areas provide a lot of policy support to the graduate education, and guarantee the healthy development of graduate education.

In Hong Kong, in order to attract good-quality students to come to Hong Kong to pursue graduate studies, Hong Kong SAR Government has specially established the University Education Funding Council, which is responsible for providing financial aids to talented but poor students (Lin, 2003). Since the establishment of the council, the number of students receiving aid has greatly increased, covering all categories (see Table 1).

The Macao's official aid is famous. According to the government of the Macao special administrative region No. 25/2004 Approval of the Chief Executive of Macau Government, in 2004 the government established the Technical Committee of Graduate Grants. The committee is responsible for developing, implementing, coordinating and following up specifications for the grant process of graduates for master's degree and doctor's degree as the permanent residents of Macao Special Administrative Region. The committee is operated by the Secretary for Social and Cultural Affairs. The Director of Tertiary Education Services Office serves as the Chairman. In addition, in 2005 the government also approved the new Graduate Scholarship Granting Regulations, so as to standardize the graduate scholarship granting. The graduate scholarship is granted to the permanent residents Macao studying in colleges and universities in Macao and other places for a master's or doctor's degree. The eligible master and doctor graduates in schools can fill in, print and sign the application form in the online system of the Technical Committee of Graduate Grants, and submit together with the relevant documents to the office of Tertiary Education Services Office. The amount and quota of the scholarship is decided and approved by the Secretary for Social and Cultural Affairs each year.

In Taiwan the government integrated the social forces, established the policy funds, and set up the long-acting mechanism of graduate aids. Taiwan Ministry of Education and universities have contributed to and established the Higher Education Evaluation \& Accreditation Council of Taiwan, so as to solve a series of problems caused by the temporary establishment of the evaluation team. One of the main tasks of the Evaluation \& Accreditation 


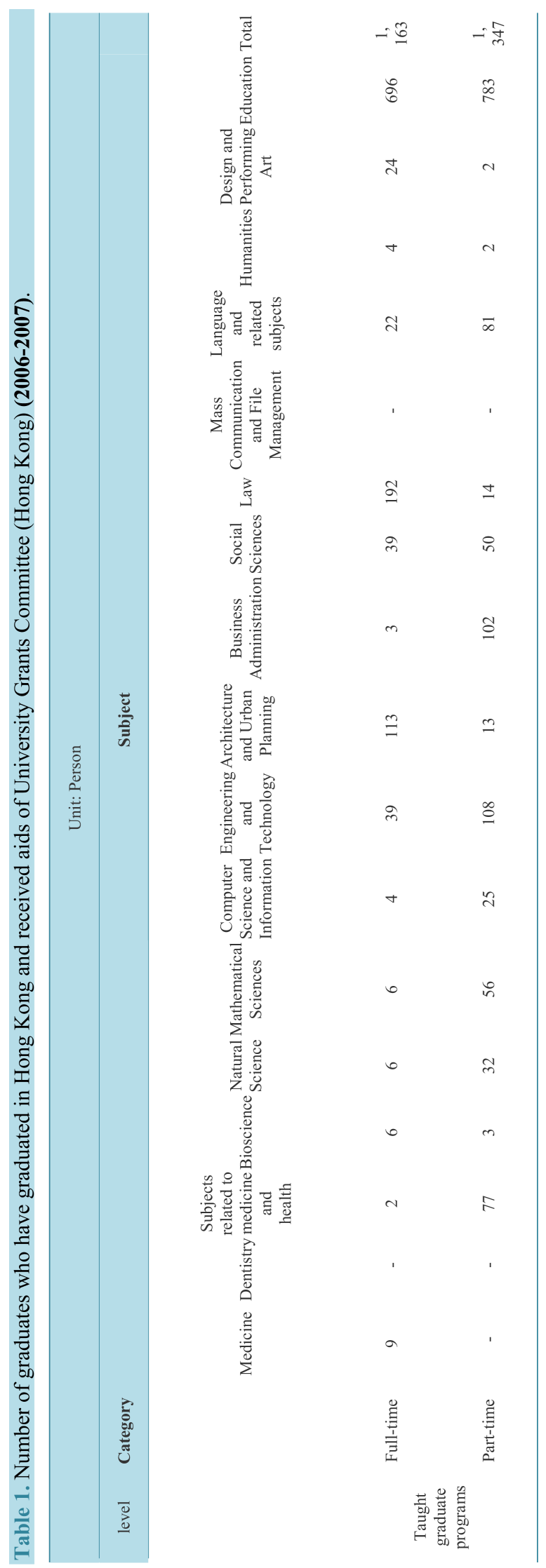

1346 
Council is the university education quality evaluation entrusted by the Ministry of Education and some evaluation and accreditation work (Cheng, 2003). In addition to the evaluation organization, in Taiwan there is Taiwan Assessment and Evaluation Association, Institute of the Engineering Education Taiwan, Center for Educational Research and Evaluation of National Taiwan Normal University and other evaluation and accreditation organizations (Zhou et al., 2008).

\section{Thinking on Graduate Education in Mainland}

The graduate training mechanism in Hong Kong, Macao and Taiwan is widely recognized in the world due to distinct style and better training effect, which will have heuristic meaning for graduate training mechanism reform in mainland.

1) Deeply recognize and grasp law of graduate education and prepare graduate training target in a scientific manner. In the age of education nationalization and talent globalization, the law of graduate education should be deeply recognized. Only the inherent law of graduate education is recognized, the graduate training target can be identified in a scientific manner. The graduate education institution framework can be identified, and weaknesses in existing graduate education can be reformed at the root. The education departments and colleges in Hong Kong, Macao and Taiwan can recognize the graduate education law in a scientific manner and can better solve the issue "what and how graduates should be cultivated". E.g. when the academic quality is ensured, graduate education actively orients to the market in Hon Kong, so it improves coupling of education resources and market resources and forms market-oriented graduate training mechanism. It is an innovative recognition in graduate education idea. The graduate education will also orient to the market in the mainland. It is necessary to actively explore the hybrid graduate training mechanism orienting to science and market and build up the marketoriented elites.

2) Grasp graduate training mechanism reform based on the idea of “quality is the life”. Graduate education aims to cultivate higher talents for the country and society, therefore, graduate training quality is the lifeline for graduate education. It is a general conclusion. The graduate training quality has international influence in Hong Kong, Macao and Taiwan, which is a huge success. The graduate training mechanism in the mainland can refer to the highlights in graduate education in Hong Kong, Macao and Taiwan. E.g. the enrollment examination mechanism should be reformed to completely and scientifically select first-class students. The existing pattern should not be completely discarded and the enrollment examination method of Hong Kong, Macao and Taiwan is used without change in reform of the enrollment examination institution. The enrollment examination institutions should be reformed incompletely. Otherwise, the problems can not be solved at the root. To improve training quality in graduate education, it is required to advocate the supreme position of the science, erect academic independence, promote academic inclusiveness, and stick to academic merit, academic personality and academic specification. If the graduate education deviates from the science, any reform will fail. The strict science requirements should be referred in graduate training in Hong Kong, Macao and Taiwan. Based on compliance to the academic law, the scientific and reasonable academic evaluation system should be prepared to truly encourage innovative development of graduates, make the graduates with academic potential and capability show themselves, and become the talents for country and society.

3) Scientifically identify positions and functions of governments and colleges in graduate education. This issue involves governmental adjustment and control, independent and administrative control of colleges, and academic specification and is the key and difficulty in graduate training mechanism reform in the mainland. As we are known, the graduate education can ensure full academic independence and freedom of colleges and does not weaken supervision and coordination of the governments in Hong Kong. Governments have influences in student enrollment registration, certificate evaluation and employment policy. It can ensure flexibility of graduate education in Hong Kong. The key issues include disorderly roles of governments and colleges and excessive intervention of administrative power to academic power in graduate training mechanism in the mainland, so the graduate training quality is not ideal. By referring to the experiences in Hong Kong, Macao and Taiwan, first the governments and colleges should be separated. The independence right of the colleges should be ensured. The administration features of colleges should be eliminated to most extent. The institutions should be performed. The intervention of administrative resources to academic resources should be prevented. The scientific and reasonable training mechanism should be established to meet the graduate training law and drive sustainable development of graduate education. 
In a word, the mainland should refer to the training mechanism of graduate education in Hong Kong, Macao and Taiwan in idea, institution and method for breakthrough in essence.

\section{Conclusion}

Graduate education has evolved much and has got many achievements in recent 20 years in Hong Kong, Macao and Taiwan. The key is to form training institution meeting local conditions. The degree and graduate education in Hong Kong focuses on academic pattern. The graduate education in Macao and Taiwan closely focuses on social reality. The graduate training mechanism can facilitate innovative talents to show themselves in Hong Kong, Macao and Taiwan. Comparing the graduate education in Hong Kong, Macao and Taiwan, the Hong Kong features deeper internationalization and academic ambience. The training mechanism in Macao and Taiwan features district local style. The reasonable parts in graduate training in Hong Kong, Macao and Taiwan should be referred and assimilated by that in the mainland.

\section{References}

Cheng, J. (2003). Statement and Comment of Current Conditions of Graduate Education in Taiwan Colleges. Technologies and Innovation Management, No. 6, 36-37.

Fan, J. (2007). Advantages and Experiences of Graduate Training in Hong Kong Colleges. Education and Modernization, 82, 40-43.

Lin, W. (2003). Comparison of Several Keys in Graduate Education in Hong Kong and Mainland Colleges. Heilongjiang Higher Education Research, 113, 155-157.

Macao Higher Education Assistance Office (1994) Macao Higher Education Law. Macao: Macao Higher Education Assistance Office

Wang, Z. (1997). Degree Institution and Graduate Education Research in Hong Kong, Macao and Taiwan. Beijing: Renmin University of China Press.

Zhou, H. et al. (2008). Discussion on Index System of Higher Education Globalization. Higher Education Research, 29, 1120. 